\title{
OUTROS DIÁLOGOS ENTRE PROFESSOR E ALUNO: A REINVENÇÃO DO LIVRO DIDÁTICO NA SALA DE AULA
}

\section{OTHER DIALOGUES BETWEEN TEACHER AND STUDENT: THE REINVENTION OF THE TEXTBOOK IN THE CLASSROOM}

\section{OTROS DIÁLOGOS ENTRE PROFESOR Y ALUMNO: LA REINVENCIÓN DEL LIBRO DIDÁCTICO EN LA SALA DE CLASE}

\author{
LINDEMEYER, Maurício Ramos \\ mrlindemeyer@hotmail.com \\ Secretaria de Estado de Educação - SEDUC - PA \\ COSTA, Vânia Maria Torres \\ vaniatorrescosta@gmail.com \\ Universidade Federal do Pará - UFPA
}

\begin{abstract}
RESUMO Este artigo propõe outros modos de leitura do livro didático a partir da análise de produções discursivas sobre o indígena brasileiro. Tendo como objeto o livro Diálogo, utilizado nas escolas públicas de Belém-PA, pretende-se apresentar o resultado de novas interações com o livro a partir da pesquisa-ação, proposta por Michel Thiollent, na qual aluno e professor tornam-se protagonistas de outras possíveis leituras do indígena, transgredindo poderes e saberes históricos e culturalmente reconhecidos nos textos oficiais. As reflexões sobre discurso como prática social, defendidas por Michel Foucault, norteiam este trabalho, permitindo apreender os textos do livro didático como enunciados, que, por meio de outros usos e provocações realizados coletivamente entre professor e aluno, são geradores de processos de reinvenção que estimulam outros diálogos em sala de aula.
\end{abstract}

PALAVRAS-CHAVE: Belém.Indígena. Leitura. Livro Didático. Pesquisa-Ação

\begin{abstract}
This paper proposes other ways of reading the textbook from the analysis of discursive production on the Brazilian indigenous. Having as object the book 'Diálogo', used in the public schools of Belém - PA, we intend to present the results of new interactions with the book from the action-research proposed by Michel Thiollent, in wich student and teacher become protagonists of other possible readings of the indigenous, transgressing powers and historical knowledge and culturally recognized in the official texts. The reflections on discourse as a social practice, defended by Michel Foucault, guide this work, allowing to apprehend the texts of the textbook as statements, which, through other uses and provocations carried out collectively between teacher and student, are generators of reinvention processes that encourage other dialogues in the classroom.
\end{abstract}

KEYWORDS: Belém. Indigenous. Reading. Textbook. Research-Action.

RESUMEN Este artículo propone otros modos de lectura del libro didáctico a partir del análisis de producciones discursivas sobre el indígena brasileño. Teniendo como objeto el libro Diálogo, utilizado en las escuelas públicas de Belém-PA, se pretende 
presentar el resultado de nuevas interacciones con el libro a partir de la investigaciónacción, propuesta por Michel Thiollent, en la que alumno y profesor se convierten en protagonistas de "otras posibles lecturas del indígena, transgrediendo poderes y saberes históricos y culturalmente reconocidos en los textos oficiales. Las reflexiones sobre el discurso como práctica social, defendidas por Michel Foucault, orientan este trabajo, permitiendo aprehender los textos del libro didáctico como enunciados, que, por medio de otros usos y provocaciones realizados colectivamente entre profesor y alumno, son generadores de procesos de reinvención que estimulan otros diálogos en el aula.

PALABRAS CLAVE: Belén. Indígena. La lectura. Libro Didáctico. La investigaciónacción

\section{INTRODUÇÃO}

A escola, como uma das instituições da modernidade, como bem analisou Michel Foucault (2007), foi criada para formar sujeitos aptos às novas exigências do capitalismo. A utilidade do trabalho, como condição para a dignidade, deveria justificar, implicitamente, o controle sobre o corpo e a disciplina, tornando-o 'um aparelho de aprender'. Cada indivíduo, assim, atraído para o ambiente da escola, passaria a ser classificado, aprovado e enquadrado como apto ou não ao mercado de trabalho.

Hoje, nas primeiras décadas do terceiro milênio, que escola temos e que sujeitos estão sendo formados nesse ambiente? Os longos anos que passamos nos bancos escolares nos fazem pensar precariamente ou limitam nossas possibilidades de reflexão? E como seria propor algo inovador ou diferente? Pensar a tríade alunoprofessor-material didático, em um contexto amazônico, é consequência de uma inquietação sobre a educação e suas relações de aprendizado, interação e comunicação tecidos no dia a dia da sala de aula, no contexto da escola pública do Norte do país, realidade, em geral, desconhecida da maioria dos não amazônicos.

A formação de sujeitos aptos a uma leitura crítica do mundo deveria atravessar a educação básica, como espaço de produção de conhecimento, de acesso à informação e de diálogos reflexivos. Mas, na prática cotidiana da escola pública, locus desta pesquisa que trazemos aqui, observa-se o modo como o livro didático figura quase como o "único suporte" (CORACINI, 2002, p. 19) para a leitura de processos sociais, culturais e históricos. 
O percurso da pesquisa começa com a inquietação de um professor de escola pública, em Belém, capital do Estado do Pará, com formação em Letras, que se dispôs a buscar saídas para os usos corriqueiros do livro didático em sala de aula e para a incipiente produção acadêmica sobre o ensino-aprendizagem de leitura e interpretação de textos, a partir de uma perspectiva discursiva.

É desta forma que chegamos ao problema da controversa seleção do livro didático. O livro didático de língua portuguesa, intitulado 'Diálogo', além de não ter sido o escolhido pelos professores ${ }^{1}$ da escola inserida no contexto da pesquisa, tem problemas no que diz respeito ao modo como representa sujeitos historicamente subalternizados, como os indígenas brasileiros. A situação é preocupante porque se trata do livro-base, leitura principal que se propõe a dialogar com adolescentes em formação, livro que constitui ferramenta de professores que, sem outras alternativas de materiais didáticos, em geral, terminam por acatar as propostas do $L^{2}$.

A partir das reflexões de Foucault $(1995 ; 1996 ; 2012)$ sobre como se instaura um certo discurso em um campo de saber, observamos textos e imagens que mobilizam o 'ser indígena' na educação básica. Pretende-se seguir os caminhos da pesquisa-ação (THIOLLENT, 2011) para investigar se é possível construir um ensinoaprendizagem visando à formação de leitores críticos, tendo por base o livro Diálogo, objeto de nossa pesquisa (BELTRÃO; GORDILHO, 2009a; BELTRÃO; GORDILHO, 2009b; BELTRÃO; GORDILHO, 2009c). Vamos problematizar a inserção do professor-pesquisador em um projeto de leitura com alunos do $9^{\circ}$ ano do ensino fundamental da Escola Estadual Santo Afonso, na periferia de Belém. A pesquisaação, realizada dentro da sala-de-aula, permite observações, em um primeiro momento, e aponta novos caminhos para lidar com problemas historicamente construídos, tais quais a dissociação entre conteúdos programáticos e os contextos sociais e históricos, de onde emergem os sujeitos e suas invenções cotidianas, na perspectiva do que nos propõe Michel de Certeau (1994).

\section{CULTURA, IDENTIDADE E O MUNDO DO TEXTO}

\footnotetext{
${ }^{1}$ Os livros didáticos de Língua Portuguesa do Ensino Fundamental dos anos $6^{\circ}$ ao $9^{\circ}$ da Coleção "Diálogo" foram enviados à Escola "Santo Afonso" pelo PNLD (Programa Nacional do Livro Didático), triênio 2011-2013. Faz parte das ações do FNDE - Fundo Nacional de Desenvolvimento da Educação, do Ministério da Educação. O MEC não justificou os motivos da escolha dos livros.

${ }^{2}$ A sigla LD será utilizada para nomear o livro didático no decorrer deste trabalho.
} 


\section{Atos de Pesquisa em Educação - ISSN 1809-0354 \\ Blumenau, v. 13, n.3, p.620-636, set./dez. 2018 \\ DOI: http://dx.doi.org/10.7867/1809-0354.2018v13n3p620-636}

Pensar sobre narrativas é pensar sobre textos que constroem o mundo, sobre modos de ordenar a vida, de nomear, de dizer sobre o 'outro'. São sistemas partilhados de significação, resultantes de consensos sobre como classificar as coisas (WOODWARD, 2000). São vivências culturais que não se fazem à margem de interações construídas no diálogo. O texto é resultante de uma seleção, recorta, produz sentidos sobre coisas, antes fragmentadas, que passam a se constituir nas narrativas, sejam orais, verbas, gestuais ou mediadas por dispositivos e meios tecnológicos.

Bakhtin (2006, p. 31) diz que os sentidos do texto vêm de fora, do rastreamento dos sujeitos em ação. "Tudo que é ideológico possui um significado e remete a algo situado fora de si mesmo. Tudo que é ideológico é um signo. Sem signos não existe ideologia". Se toda produção discursiva é ideológica, então todo texto é produtor de identidades, porque permite a relação entre 'mim' e o 'outro' ou entre 'nós' e 'eles'. 'A identidade e a diferença têm que ser ativamente produzidas. Elas não são criaturas do mundo natural ou de um mundo transcendental, mas do mundo cultural e social" (SILVA, 2000, p. 76).

Identidade e diferença, desse modo, são produzidas por meio de práticas discursivas; são atravessadas por contextos históricos, "ativos e responsivos", como nos aponta Bakhtin (2011, p. 271). Mergulhando nas tramas de um determinando campo de enunciados e saberes, como o da educação, identificamos os discursos socialmente aceitos, canônicos e a negação de saberes e vivências silenciadas, como os povos indígenas.

Barth (2000, p. 132) nos diz que é preciso prestar "muita atenção às pistas relativas ao contexto, à práxis, à intenção comunicativa e à interpretação" para entender o mundo construído pelo 'outro'. Já Certeau (2010, p. 09), mais contundente, aponta que toda escrita é colonizadora, porque visa à "colonização do corpo pelo discurso do poder". Há sempre, no texto em questão, o poder do autor de dizer e, ao mesmo tempo, de silenciar, de inserir o 'outro' na página, com a cor, o tamanho e o perfil, submetidos a uma determinada visão de mundo, um determinado olhar, um ponto de vista e não outro.

Passaremos agora a adentrar no modo como os indígenas vêm sendo representados nas narrativas nacionais, que mobilizam diversos campos do saber, tais quais a escola, a igreja, a ciência, a literatura e a mídia, entre outros. 


\section{A INVENÇÃO DO ÍNDIO: ESCOLA À VISTA}

O debate sobre a representação dos indígenas na sociedade brasileira leva-nos a problematizar sobre o modo como as relações de poder-saber do sistema colonial administraram sentidos do "índio genérico, antropófago, sem roupa, sem conhecimento e de mentalidade primitiva" (NEVES, 2009, p.28). E é nas práticas discursivas contemporâneas que encontramos a chave para analisar a herança cultural desse complexo sistema, ao observar os modos como os discursos forjam sistematicamente os objetos de que falam, entre os quais e, especialmente, forjam os indíviduos (FOUCAULT, 2012). Logo, refletir sobre a 'invenção' do índio' na escola demandará, de um lado, ler e interpretar criticamente as estratégias coloniais e, de outro, entender as práticas culturais dos povos indígenas na contemporaneidade.

No entanto, não acreditamos que a História dos indígenas brasileiros esteja apenas pautada em subjugação. Tanto que pesquisas recentes, tais como Corrêa (2013), Neves (2009), Silva (2013) e Tocantins (2012), não deixam que olvidemos que os indígenas, na medida de suas possibilidades históricas, resistiram e resistem ainda ao poder de ação do colonizador. Por isso, os diversos grupos têm reinventado suas tradições e inscrito suas memórias na atualidade mesmo frente à relação tão desigual com os poderes coloniais e neocoloniais. Os discursos contra hegemônicos aparecem nos nossos hábitos alimentares, na grande influência na atual língua portuguesa, bem como nas narrativas que materializam as cosmologias das sociedades indígenas na Amazônia, tais como aquelas intituladas de "Como apareceu a noite" e "A criação da noite", contadas por ribeirinhos no Marajó, Pará, e registradas por Silva (2013) em sua pesquisa.

"A ignorância colonialista consiste na recusa do conhecimento do 'outro' como igual e na sua conversão em objeto" (SANTOS, 2004), esse movimento estaria relacionado aos discursos que vêm sendo historicamente construídos desde os viajantes europeus, entre os quais destacamos o navegador Cristóvão Colombo e o escrivão português Pero Vaz de Caminha, discursos que percorrem boa parte da literatura nacional, dentre elas as obras canônicas como "Iracema" e "O Guarani", de José de Alencar, em que os sentidos se organizam "a partir da submissão [dos indígenas] ao português" (NEVES, 2009, p.40) e projetam um índio sempre inferior aos outros grupos culturais. 
Conquanto essa reflexão demande um olhar mais detido, passa-nos a interessar o modo como os discursos sobre os indígenas são movimentados na escola pública. Nosso estudo, tal qual já foi mencionado, partiu da análise discursiva da coleção "Diálogo", de autoria de Beltrão e Gordilho (2009).

Os quatro livros da coleção "Diálogo" trazem onze textos sobre a temática indígena, os quais podem ser divididos segundo seus objetivos pedagógicos: três fazem parte da seção "Trabalhando a Gramática", cujo objetivo é usar o texto para o ensino da nomenclatura gramatical; três outros estão na seção "Ampliando o Tema" e servem para complementar um assunto em debate no capítulo; e ainda outros três são indicados para serem usados como leitura, mas cujas atividades também tratam sobre aspectos da nomenclatura gramatical. Por fim, dois textos estão no espaço "Reservado para o humor", no qual a leitura não é dirigida pelo LD. Por ser objeto de nossa análise discursiva, esses onze textos aparecem mapeados no quadro abaixo (ver tabela 1):

Tabela 1: Mapeamento do texto quanto às instituições

Fonte: os autores

\begin{tabular}{|c|c|c|}
\hline Temática & Instituição/Editora & Autor(es) \\
\hline Lenda da Vitória-Régia & Editora Edgraf & Folclore brasileiro \\
\hline Estória de "Lucas O Pescador" & Editora FTDT & Daniel Munduruku \\
\hline Retrato sobre "O índio" brasileiro & Editora FTD & Orlando Villas Bôas \\
\hline Economia dos Wajãpi & Museu do Índio/USP & Catharina J.S. Gollois \\
\hline $\begin{array}{c}\text { Regra nas sociedades Xavantes } \\
\text { Os Pancaré e o movimento } \\
\text { cangaceiro }\end{array}$ & Folha de São Paulo & Folha de São Paulo \\
\hline $\begin{array}{c}\text { A leitura nas sociedades indígenas } \\
\text { Oúltimo Quarup, de Orlando Villas } \\
\text { Bôas }\end{array}$ & ONG Leia Brasil & Revista Legis \\
\hline $\begin{array}{c}\text { Charge sobre a perplexidade do } \\
\text { índio nas sociedades urbanas }\end{array}$ & Revista Raiz & Orlando Villas Bôas \\
\hline $\begin{array}{c}\text { A formação dos índios e suas } \\
\text { identidades }\end{array}$ & Revista Galileu & Maria Villas Bôas \\
\hline $\begin{array}{c}\text { Educação Indígena } \\
\text { Museu do índio (RJ) }\end{array}$ & Fabio dos Santos \\
\hline
\end{tabular}

A análise discursiva desses textos, pautada nas regularidades e dispersões (FOUCAULT, 2012, p. 66) dos sentidos, deu-nos ensejo de apontar que as sociedades indígenas estão sendo narradas segundo três regularidades, quais sejam: a posição 
de autor, a enunciação da identidade pela diferença e o índio como um "bom selvagem".

Entendendo o autor como um "princípio de agrupamento do discurso, como unidade e origem de suas significações, como foco de sua coerência" (FOUCAULT, 2012, p.26), percebemos que o processo de agenciamento dos discursos sobre as sociedades indígenas no LD "Diálogo" se dá de forma centralizada, tanto institucional quanto geograficamente, conforme materializa o quadro acima.

Como vemos, o LD privilegia, então, um modo próprio para narrar sobre os indígenas. No geral, são pessoas apresentadas como "civilizadas" e ligadas a instituições sediadas no Sudeste do Brasil, pertencentes a grupos comunicacionais, entre eles os jornais, revistas e editoras. Exemplos de fuga a esse controle seriam os textos de Daniel Munduruku e Jorge Terena, que seriam representantes de sociedades indígenas, que, no entanto, estão sob certo controle discursivo, já que ambos são apresentados associados ao saber acadêmico. Daniel é nascido "no Pará e formou-se em Filosofia nas Faculdades Salesianas de Lorena" (BELTRÃO; GORDILHO, 2009a, p.169) e Terena é autor do "texto que expõe o ponto de vista do sociólogo Jorge Terena" (BELTRÃO; GORDILHO, 2009a, p.257). Logo, a graduação que cursaram os legitima; ela passa - mais do que os pertencimentos às suas culturas - a ser instrumento de autorização de suas falas no LD em questão.

Por sua vez, outros trajetos de sentidos no LD nos obrigam a analisar a relação entre identidade e diferença. O livro "Diálogo" constantemente produz sentidos de que há duas identidades sendo narradas, o "eu", que representa as pessoas da cidade com suas culturas mais complexas, e o "outro", que se refere ao indígena posicionado na condição de habitante das florestas, habituado às narrativas orais com "elementos fantásticos, misteriosos e sobrenaturais" (BELTRÃO; GORDILHO, 2009a, p.107). Os indígenas servem como referência para que o "eu" possa reconhecer-se, isto é, a identidade se constituindo frente à diferença do "outro" (HALL, 2011).

Algumas materialidades do LD sustentam a análise. Trataremos de duas: com frequência, existe a definição do "eu" na condição do civilizado, como na seguinte passagem: "O Quarup, de Orlando Villas Bôas, em 2003, foi a maior homenagem que se fez até hoje a um civilizado dentro da cultura indígena" (BELTRÃO; GORDILHO, 2009a, p.124). Aqui se torna explícita a condição do indígena como selvagem e, portanto, não civilizado. Mas a enunciação sobre o 'outro' não para por aí, como na charge que segue (figura 1): 
Figura 1: Charge 'índios na cidade'

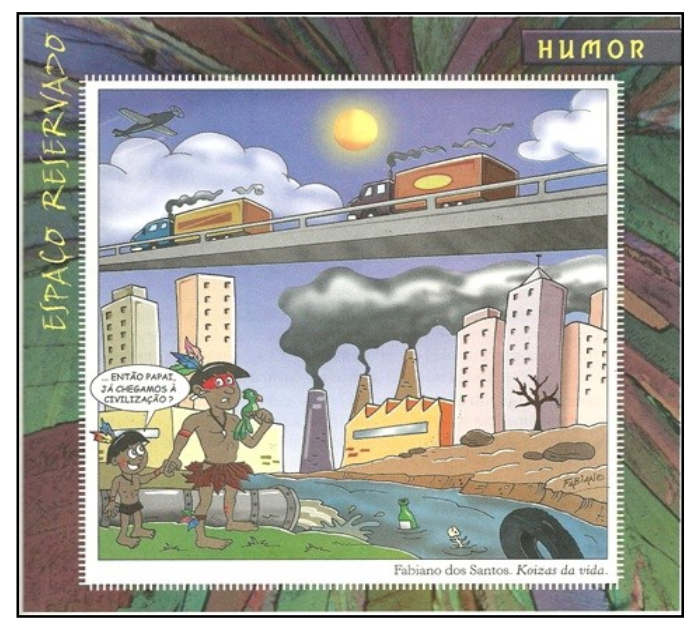

Fonte: BELTRÃO; GORDILHO, 2009, p.137

O texto e a imagem dessa charge representam os indígenas na margem do rio, porém, as margens não são os "entre-lugares" de que fala Bhabha (1998), isto é, o espaço cultural onde as culturas se encontram e interagem, no qual há negociação e tensão. A charge estabiliza a margem enquanto local que separa os indígenas das demais sociedades urbanas e o rio serve, neste caso, como um meio a mais de indicálo como o que 'está fora'. A fala do personagem criança ajuda a produzir esses sentidos: "então pai, já chegamos à civilização?"

Essa charge ainda nos incita a refletir sobre a última regularidade sobre os índigenas já anunciada: a questão do "bom selvagem". Muitos textos, entre eles o da 'figura 1', tratam o indígena na condição daquele que é alheio aos problemas da sociedade brasileira, bem como daquele que vive uma vida sem conflitos por estar nas matas. Este discurso remete-nos à obra de Jean Jacques Rousseau (1997), quando ele afirma que o homem só se corrompe quando abandona a vida na natureza. Por tudo, pode-se defender que a "ordem discursiva" mantida pelo LD é aquela em que o indígena é o 'outro' e posto na condição de inferior, já que, apartado da vida contemporânea, cabe-lhe apenas a identidade de um ser ingênuo, limitado, porém bom.

\section{OUTROS DIÁLOGOS NA SALA DE AULA}

Até aqui refletimos sobre o Livro Didático "Diálogo" como uma agência produtora de discursos. Sua entrada autoritária em sala de aula, aqui já mencionada, 
e boa parte das mediações que são feitas por meio dele autorizam o que deve ser lido e os sentidos a serem privilegiados em sala de aula. Nessa instauração do 'discurso verdadeiro' (FOUCAULT, 1996), o LD põe em circulação e a escola costuma acatar os discursos que estigmatizam os grupos subalternizados, entre os quais, as sociedades indígenas.

No entanto, somos daqueles que defendem ser este problema uma questão de mediações mais do que de meios (MARTíN-BARBERO, 2009). Assim, buscamos desenvolver uma pesquisa pautada na tentativa de promover um ensino crítico de leitura, saindo, portanto, dos sentidos que estimulam a promoção de estereótipos no LD para a construção de outros caminhos de leitura. Bhabha (1998, p.105) trata assim o estereótipo: principal estratégia discursiva [discurso colonial]. É uma forma de conhecimento e identificação que vacila entre o que está sempre "no lugar", já conhecido, e algo que deve ser ansiosamente repetido.

Por isso, propusemos desenvolver a pesquisa-ação junto a uma turma do $9^{\circ}$ ano do ensino fundamental. Optamos por esta modalidade de pesquisa porque ela visa à análise de situações problemáticas e à busca de uma possível solução: a pesquisaação é um tipo de pesquisa social com base empírica que é concebida e realizada em estreita associação com uma ação ou com a resolução de um problema coletivo e no qual os pesquisadores e os participantes representativos da situação ou do problema estão envolvidos de modo cooperativo ou participativo (THIOLLENT, 2011, p.20).

A escolha da turma está também implicada com os preceitos da pesquisa-ação, pois foi escolhida uma turma no $9^{\circ}$ do ensino fundamental, cujos alunos foram nossos discentes em anos anteriores na mesma escola pública, e aquilo que os qualificou foi o uso do LD "Diálogo" durante três anos. Assim, o caminho pelo qual pautamos nossa pesquisa parte de uma inquietação específica: a promoção de discursos estereotipados pelo livro didático "Diálogo" e a necessidade de promover um ensino crítico de leitura de modo a que outros sentidos sejam movimentados em sala de aula, diferentes daqueles privilegiados pelo LD.

$\mathrm{Na}$ esteira da pesquisa-ação, as aulas foram organizadas de modo a possibilitar a leitura, o diálogo e a releitura de quatro textos do LD "Diálogo" da seguinte forma (ver tabela 2):

Tabela 2: Aulas de leitura e coleta de dados

\begin{tabular}{|c|c|c|}
\hline Texto & Semana & Leitura \\
\hline
\end{tabular}


Atos de Pesquisa em Educação - ISSN 1809-0354

Blumenau, v. 13, n.3, p.620-636, set./dez. 2018

DOI: http://dx.doi.org/10.7867/1809-0354.2018v13n3p620-636

\begin{tabular}{|l|c|l|}
\hline \multirow{2}{*}{ "A Lenda da Vitória Régia"3 } & 01 & Em grupos de alunos \\
\cline { 2 - 3 } & 02 & $\begin{array}{l}\text { Com intervenção do professor- } \\
\text { pesquisador }\end{array}$ \\
\hline \multirow{2}{*}{ "O Índio"4 } & 03 & Em grupos de alunos \\
\cline { 2 - 3 } & 04 & $\begin{array}{l}\text { Com intervenção do professor- } \\
\text { pesquisador }\end{array}$ \\
\hline \multirow{2}{*}{ "Terra e Aldeia dos Wajãpi"5 } & 05 & Em grupos de alunos \\
\cline { 2 - 3 } & 06 & $\begin{array}{l}\text { Com intervenção do professor- } \\
\text { pesquisador }\end{array}$ \\
\hline índio com diploma não é mais & 07 & Em grupos de alunos \\
\cline { 2 - 3 } & 08 & Sem atividade de leitura \\
\hline
\end{tabular}

Fonte: os autores

Cada texto foi trabalhado em sala de aula durante duas semanas, sendo que, na primeira semana os alunos leram individualmente e, depois, em grupos, conversaram sobre suas leituras e responderam em uma folha a opinião do grupo sobre pontos do texto. Já na segunda semana a releitura foi feita entre o professorpesquisador e os alunos, a partir da qual se retomaram os sentidos produzidos por eles na aula anterior, atravessados por novos diálogos que foram surgindo sobre o texto na discussão coletiva. Após isso, os alunos responderam novamente as mesmas questões da primeira semana, mas agora com a oportunidade de construírem novas leituras e reflexões.

Devemos lembrar, porém, que a pesquisa-ação não se constitui em teoria, o que nos remete à necessidade de buscar "quadros de referência teóricos, com base nos quais estão estruturados conceitos, as linhas de interpretação e as informações colhidas durante a investigação" (THIOLLENT, 2011, p.20). Desse modo, buscamos as reflexões teóricas sobre discurso na obra Arqueologia do Saber, de Michel Foucault, sobretudo, como categoria que baliza o processo de análise desta investigação: a formação discursiva (FD) (FOUCAULT, 2012).

Inserida no corpo teórico-metodológico dos escritos de Michel Foucault, a categoria formação discursiva (FD) diz respeito às regularidades da produção de sentidos:

No caso em que se puder descrever, entre um certo número de enunciados, semelhante sistema de dispersão, e no caso em que entre os objetos, os tipos de enunciação, os conceitos, as escolhas temáticas, se puder definir uma

\footnotetext{
${ }^{3}$ BELTRÃO; GORDILHO, 2009a, p.107-108.

${ }^{4}$ BELTRÃO; GORDILHO, 2009a, p.172- 173.

${ }^{5}$ BELTRÃO; GORDILHO, 2009b, p.122-123.

${ }^{6}$ BELTRÃO; GORDILHO, 2009c, p.122-123.
} 
regularidade (uma ordem, correlações, posições e funcionamentos, transformações), diremos, por convenção, que se trata de uma formação discursiva. (FOUCAULT, 2012, p.47).

Então, enquanto a perspectiva da pesquisa-ação nos oportunizou traçar o caminho da pesquisa, em que os sujeitos problematizaram e cooperaram para a construção de novos olhares sobre o ato de ler e a produção de identidades indígenas, a categoria formação discursiva (FD) possibilitou-nos analisar os sentidos movimentados pelos alunos entre regularidades e dispersões de suas leituras. Dito de outro modo, a noção de FD permitiu-nos analisar as práticas de leitura de cada texto. Permitiu-nos analisar os discursos movimentados pelas leituras dos alunos no momento da primeira leitura de cada texto, assim como os discursos no momento das releituras desses textos, estabelecendo um trajeto de sentidos entre regularidades de sentidos e deslocamentos. De posse dessa apreciação metodológica, passaremos à análise.

As primeiras leituras dos grupos movimentaram sentidos de prestígio à palavra alheia, conforme a figura 2 , a seguir:

Figura 2: $3^{\text {a }}$ Resposta de grupo de alunos

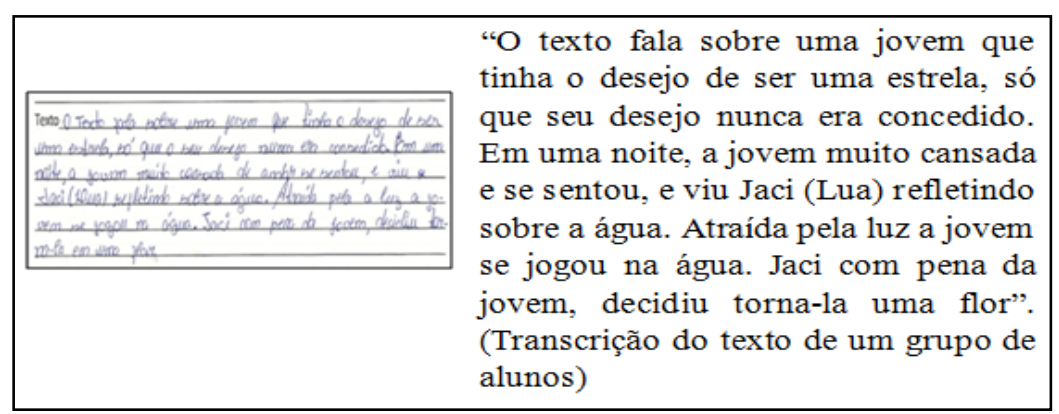

Fonte: depoimentos de alunos

Esses alunos, além de não sinalizarem que se trata de uma atividade coletiva, apresentaram uma leitura que nós entendemos como parafrástica, pois tentam reconstruir os sentidos que acreditam constar no texto. Orlandi $(2008$, p.12) afirma que a leitura parafrástica "se caracteriza pelo reconhecimento (reprodução) de um sentido que se supõe ser o do texto (dado pelo autor)". Porém, ainda que não esteja materializada em suas respostas, desde as leituras iniciais, os alunos põem em circulação redes de memórias não acionadas pelos textos do LD. Estas, para Gregolin (2005), são a própria ideia de discurso, mas com a consideração de que as formações discursivas, isto é, as regularidades dos sentidos dão-se pelo atravessamento de 
memórias discursivas. Logo, pontua-se a dinâmica da interativa/conflitiva entre as práticas de linguagem. Vejamos a conversa registrada pelo grupo, já na primeira aula:

- A lenda é um dos tópicos da cultura.

- explicação da... da criação do mundo.

- a lua foi criada...

- Como a lua foi criada?

- Big Beng... Big Bang.

- A história pelos católicos é registrada... história Cristiana...

(Registro em áudio de grupo de alunos da turma 831)

O diálogo entre os alunos, nesse momento, deu-se por meio do acionamento de duas redes de memórias, quais sejam: o surgimento do mundo visto à luz das ciências astrofísicas e do homem sob o amparo do discurso da Igreja Católica. No entanto, como adiantamos, eles não levaram esse debate para suas respostas ao responder as questões propostas, bem como até tiveram dúvidas sobre a validade desses saberes para responder sobre um texto que não apresentava esses discursos, como denuncia o debate no grupo:

-Pois é... Ah, meu Deus! Sabe o que é engraçado?

-O quê?

-É que em vez de vocês estarem debatendo sobre português e vocês estão falando em ciência...

-A gente estava pensando em ciência? (risos)

- Não! Não! Acredito... (Registro em áudio de grupo de alunos da turma 831)

Como adiantamos, depois de cada primeira leitura, o professor-pesquisador e os alunos faziam uma releitura coletiva do texto, na qual nós problematizávamos os discursos movimentados pelos alunos no primeiro momento, a fim de que eles se permitissem estabelecer outros diálogos com os textos trabalhados. Os percursos das aulas, porém, levam-nos a falar sobre importantes deslocamentos de leitura dos alunos. Vejamos o exemplo da figura 3 :

Figura 3: $3^{a}$ Resposta de grupo de alunos

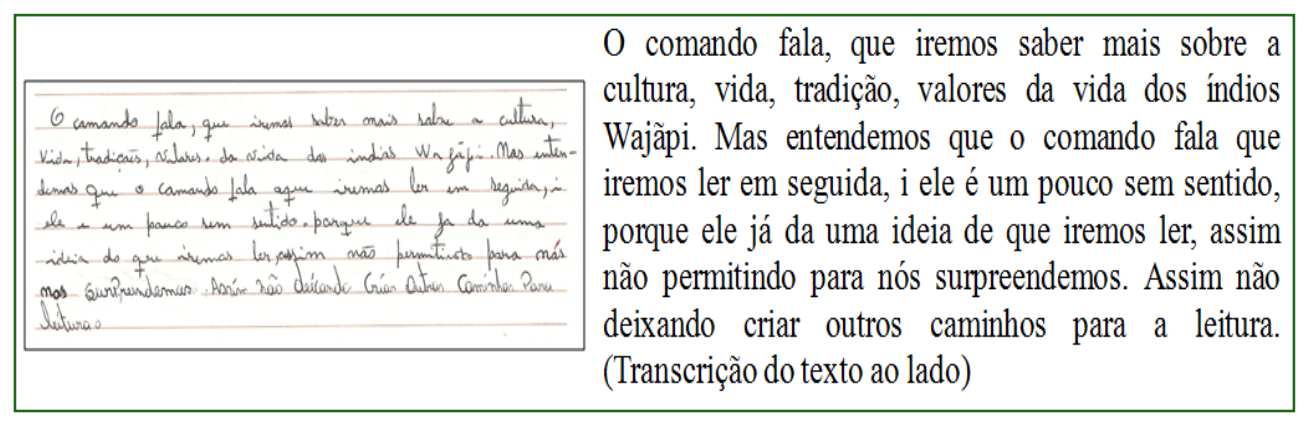




\section{Atos de Pesquisa em Educação - ISSN 1809-0354 \\ Blumenau, v. 13, n.3, p.620-636, set./dez. 2018 \\ DOI: http://dx.doi.org/10.7867/1809-0354.2018v13n3p620-636}

$\mathrm{Na}$ leitura do terceiro texto, portanto, na quinta semana do projeto de leitura, este grupo sente a necessidade de se opor ao "discurso verdadeiro" que o LD tenta instaurar, tanto que eles utilizam um termo usado pelo professor-pesquisador, desde o contato inicial com a turma, cuja finalidade era a de apresentar o leitor como aquele que caminha, opta por destinos, negocia com o espaço da caminhada (CERTEAU, 1994), qual seja a expressão extraída de depoimento dos alunos, conforme figura 3 : "assim não deixando criar outros caminhos para a leitura".

Por fim, temos a leitura do próximo grupo, figura 4 , de modo que possamos visualizar o deslocamento das posições iniciais para aquelas em que os alunos passaram a questionar os sentidos "verdadeiros" que o LD movimenta:

Figura 4: $3^{\mathrm{a}}$ resposta de grupo de alunos

\begin{tabular}{|c|c|}
\hline 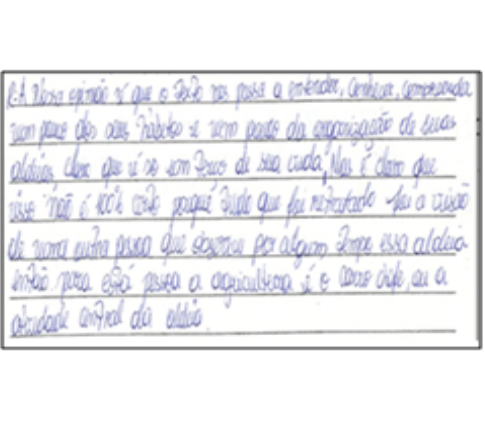 & $\begin{array}{l}\text { A nossa opinião é que o texto nos } \\
\text { passa a entender, compreender um } \\
\text { pouco dos seus hábitos e um pouco da } \\
\text { organização de suas aldeias, claro que } \\
\text { é só um terço de sua vida. Mas é claro } \\
\text { que isso não é } 100 \% \text { certo porque } \\
\text { tudo foi retratado foi a visão de uma } \\
\text { outra pessoa que observou por algum } \\
\text { tempo essa aldeia então para está } \\
\text { pessoa a agricultura é o carro chefe, } \\
\text { ou a atividade central da aldeia. } \\
\text { (Transcrição do texto ao lado) }\end{array}$ \\
\hline
\end{tabular}

Fonte: depoimento de aluno

O grupo questiona a autoria do texto: "foi a visão de uma outra pessoa que observou por algum tempo essa aldeia" e, com isso, reivindica a necessidade de escuta de pessoas que pertencem e vivem nas sociedades indígenas. $E$ os alunos vão além: posicionam-se como leitores que têm no texto um momento de diálogo (GERALDI, 1996) e um dos momentos privilegiados de produção do mundo pelo uso da linguagem (FREIRE, 2011).

\section{CONSIDERAÇÕES FINAIS}

Certamente, a palavra tem um peso muito importante nessa pesquisa. Preocupamo-nos, assim, com a leitura nas aulas de língua portuguesa mediadas pela palavra do livro didático, que arregimenta uma ordem discursiva cujas 'ritualidades' (MARTÍN-BARBERO, 2009) costumam agenciar os textos, as possíveis posições dos 


\section{Atos de Pesquisa em Educação - ISSN 1809-0354 \\ Blumenau, v. 13, n.3, p.620-636, set./dez. 2018 \\ DOI: http://dx.doi.org/10.7867/1809-0354.2018v13n3p620-636}

sujeitos e quais efeitos de sentidos são autorizados a serem reproduzidos tanto por professores como por alunos.

No entanto, as experiências de sala de aula e as reflexões teóricas sobre as quais tecemos nossas análises, tais como as propostas de Michel Foucault, Michel de Certeau, Paulo Freire, entre outros, ensinaram-nos que, apesar da palavra do livro didático, as práticas de linguagem jamais fogem da diversidade e da tensão das palavras alheias. Inúmeras ordens discursivas nos atravessam na tentativa da estabilização e deslocamento de sentidos, por vezes contraditórios, criando-nos efeitos de memórias discursivas nos quais nos situamos ora para a produção, ora para a reprodução de discursos. Devemos, portanto, destacar, a cada palavra, uma contra palavra (BAKHTIN, 2004).

Assim, o percurso de nossa pesquisa, cuja inquietação partiu dessa ordem discursiva do LD 'Diálogo', fez-nos abordar o ensino de língua portuguesa enquanto uma prática de diálogo e do acionamento de outros sentidos que aqueles privilegiados pelo texto e postos em circulação sobre os indígenas. Notadamente, a pesquisa-ação auxiliou-nos nessa empresa, quando nossa atenção voltou-se para a possibilidade das astúcias do leitor (CERTEAU, 2009).

A interação entre o professor-pesquisador e os alunos causou rupturas nos sentidos tanto do ser leitor, do ser professor, do ser aluno, e do que seja ser índio na escola e sociedade brasileiras. Vemos, portanto, os alunos incorporando novas estratégias de abordagem textual, como a reflexão sobre a autoria dos textos em virtude dos sentidos que movimentam, com a consequência de que foram ressignificando suas posições de leitor. Logo, o percurso do projeto de leitura evidencia, paulatinamente, a diminuição do receio dos alunos em produzirem marcas tanto nos textos quanto nas redes de memórias sobre os modos de representação do indígena.

Parece-nos lícito defender, pois, que a interação entre a promoção do diálogo e a abertura para a diversidade e a tensão entre memórias colaborou para causar fissuras na ordem discursiva sustentada pelo livro com claros benefícios pedagógicos: o aluno se assumindo enquanto sujeito de seu processo de aprendizagem, sendo cada vez mais autor de seu ato de ler, sem perder o ambiente social, já que se faz em coparticipação com os demais alunos e com o professor-pesquisador. Desse modo, atingimos, assim, não apenas a crítica à palavra do 'outro' como portadora de verdades (sem ignorar o benefício da palavra alheia), mas sabendo que é preciso, 
com mais consciência, escolher suas próprias palavras. E ainda que seja provável falar sobre insipientes processos de reinvenção, acreditamos que os alunos desenvolveram leituras, nas quais foram se apropriando dos textos com consequências para o processo de suas próprias formações. Temos convicção, desse modo, que o diálogo proporcionado por esta pesquisa oportunizou novas formas de cidadania na sala de aula.

\section{MAURÍCIO RAMOS LINDEMEYER}

Mestre em Comunicação, Linguagens e Cultura pela Universidade da Amazônia. Especialista em Língua Portuguesa - Análise Literária pela Universidade da Amazônia. Atualmente é Professor do E.E.E.F. Santo Afonso e Professor da EEEFM Antônio Moreira Junior.

\section{VÂNIA MARIA TORRES COSTA}

Jornalista. Doutora em Comunicação pela Universidade Federal Fluminense (UFF). Mestre em Planejamento do Desenvolvimento (NAEA/UFPA). Professora adjunta da Universidade Federal do Pará, com atuação na Faculdade de Comunicação.

\section{REFERÊNCIAS}

BAKHTIN, M. M. Marxismo e filosofia da linguagem. 12. ed. São Paulo: Hucitec, 2004. . Estética da criação verbal. 6.ed. São Paulo: WMF Martins Fontes, 2011.

BARTH, F. O guru, o iniciador e outras variações antropológicas. Rio de Janeiro: Contracapa, 2000.

BELTRÃO, E. L. S.; GORDILHO, T. C. S. Diálogo: língua portuguesa, $6^{\circ}$ ano. São Paulo: FTD, 2009a. . Diálogo: língua portuguesa, $7^{\circ}$ ano. São Paulo: FTD, 2009b. . Diálogo: língua portuguesa, $9^{\circ}$ ano. São Paulo: FTD, 2009c.

BHABHA, H. K. O local da cultura. Belo Horizonte: Editora da UFMG, 1998.

CERTEAU, M.. A Invenção do cotidiano: artes de fazer. Petrópolis, RJ: Vozes, 1994.

CORACINI, Ma. J. (Org.). O jogo discursivo na aula de leitura. 2. ed. Campinas, SP: Pontes, 2002. 
CORREAA, M. N.. Os Aikewára e a mídia: relações de poder, cultura e mediação. Dissertação (Mestrado em Comunicação, Linguagens e Cultura) Universidade da Amazônia, Belém/PA, 2013.

FOUCAULT, M.. O sujeito e o Poder. In: RABINOW, P. \& DREYFUS, H. Michel Foucault: uma trajetória filosófica. Para além do estruturalismo e da hermenêutica. Rio e Janeiro: Forense Universitária, 1995.

. A Ordem do Discurso: aula inaugural no Collège de France, pronunciada em 2 de dezembro de 1970. 21. ed. SP: Edições Loyola, 1996.

. Vigiar e Punir: nascimento da prisão. Tradução de Raquel Ramalhete. 34ed. Petrópolis: Vozes, 2007.

. A arqueologia do saber. 8. ed. Rio de Janeiro: Forense Universitária, 2012.

FREIRE, P. Alfabetização: leitura do mundo, leitura da palavra. Rio de Janeiro: Paz e Terra, 2011.

GERALDI, J. V. Linguagem e ensino: exercício de militância e divulgação. São Paulo: Mercado de Letras, 1996.

HALL, S.. A identidade cultural na pós-modernidade. 11.ed. Rio de Janeiro: DP\&A, 2011.

MARTÍN-BARBERO, J. Dos meios às mediações: comunicação, cultura e hegemonia. 6.ed. Rio de Janeiro: Editora UFRJ, 2009.

NEVES, I. A invenção do índio e as narrativas orais Tupi. São Paulo, 2009, 209f. Tese (Doutorado em Linguística) - Instituto de Estudos da linguagem, UNICAMP, São Paulo, 2009.

ROUSSEAU, J-J. Do contrato social: ensaio sobre a origem das línguas. São Paulo: Nova Cultural, 1997.

SANTOS, B de S. Do pós-moderno ao pós-colonial: e pra além de um e outro. Conferência de abertura do VIII Congresso Afro-luso-brasileiro de Ciências Sociais, realizado em Coimbra, de 16 a 18 de setembro de 2004.

SILVA, T. T. (Org.). A produção social da identidade e da diferença. In: Identidade e diferença: a perspectiva dos estudos culturais. Petrópolis, $\overline{R J: ~ V o z e s, ~}$ 2000.

SILVA, J. P. Memórias Tupi em narrativas orais no rio Tajapuru: Marajó das Florestas - Pa. Dissertação (Mestrado em Comunicação, Linguagens e Cultura) Universidade da Amazônia, Belém/PA, 2013.

TOCANTINS, R. A. Mulheres indígenas no facebook: corpos, intericonicidade e identidades / Raimundo de Araújo Tocantins. Dissertação (Mestrado em Comunicação, Linguagens e Cultura) Universidade da Amazônia, Belém/PA, 2012. 
THIOLLENT, M. Metodologia da pesquisa-ação. 18.ed. São Paulo, Cortez, 2011.

WOODWARD, K. Identidade e diferença: uma introdução teórica e conceitual. In: SILVA, T. T. (Org.). Identidade e diferença: a perspectiva dos estudos culturais. Petrópolis, RJ: Vozes, 2000. 133p. Cap. 1, p. 7-72. 